\title{
MOBILE BANKING IN INDIA
}

\author{
Leslie KLIEB \\ Webster University, Thailand \\ kliebl@webster.ac.th \\ Ramona- Mihaela PAUN \\ Bucharest University of Economic Studies, Romania \\ ramona.paun@csie.ase.ro \\ Chanchal MALHOTRA \\ chanchalmalhotra@hotmail.com
}

\begin{abstract}
This work presents empirical research into factors that influence consumers in India to use Mobile Banking. The work uses a model derived from the Technology Acceptance Model and its offshoots UTAUT and TAM3. Most TAM-like models have acceptance as the dependent variable. However, this work uses the likelihood to use (start using or continue using) mobile banking as a more relevant variable. The model provides a good fit to the likelihood to use mobile banking. A cross-over effect was found, in contradiction with the TAM3 model. Arguments are given as to why a cross-over is plausible for this case. The influence of peers was found to be important. We also check whether there are any differences in the way women and men do mobile banking in India and conclude that the women's stated insecurity, maybe a cultural artefact, had no influence on the participation in mobile banking.
\end{abstract}

Keywords: factors for usage of mobile banking, India, quantitative survey, TAM3, UTAUT JEL classification: O14, O32, O33.

DOI: $10.12948 / \mathrm{ie} 2019.07 .08$

\section{Introduction}

This report is part of a research project that aims to investigate quantitatively the factors that influence the Indian consumers to use Mobile Banking instead of other forms of banking for conducting financial transactions.

A number of Indian residents were approached via various social media platforms like Facebook and LinkedIn and requested to participate in a survey, and 91 of them responded. The questionnaire was mainly based on the TAM3 model of Venkatesh and Bala [1]. The empirical data was analyzed quantitatively via a network model. The respondents were residing in different cities of India, mainly the greater Delhi area, were in general educated, possessed a smart phone, were savvy about the internet and some were currently using Mobile Banking. Factors like convenience, job relevance, perceived risk, perceptions of usefulness and ease of use, computer self-efficacy, output quality of mobile application and others were considered, together with occupational status, gender and educational level. The research question of this work is "What factors influence Indian customers to use Mobile Banking?" and more in particular, "Do women use mobile banking different from men in India?"

\section{Mobile banking in India}

In 2012, more than 70\% of India's population was not using the formal banking system despite the existence of a vast network consisting of 80 commercial banks with around 77,000 branches, and much push from the government for financial inclusion [2]. Moreover, only 
about $26 \%$ of women had an account with a formal financial institution, compared with $46 \%$ of men. Reportedly, due to cultural practices and gender based financial literacy gap, many Indian women would typically give their earnings to their husbands who handle the household's finances [3]. In 2013, the country's first ever state-owned bank for women that aimed at empowering and educating women financially thus addressing gender related issues and financial inclusion was inaugurated. The government's efforts paid off as in $201780 \%$ of adults in India had a bank account with a gender gap of just $6 \%$ down from $20 \%$ in 2014 [4]. Advancements in technology created new channels through which consumers could interact with their financial institutions. A 2017 banking survey showed that in 2017, 51\% of Indians used online banking channels, with $26 \%$ accessing the services via their bank's website and a similar percentage using mobile phone apps rather than talk to a human agent [5]. Those who use banks and are willing to do electronic banking have often used mobile phones because in many cases these are the only way for consumers to connect to the Internet. About $69 \%$ of India's population owns a mobile phone [4]. However, the proportion of the Indian population accessing financial institution accounts from their phones or the Internet, making digital payments or using mobile money wallets is significantly lower than in other developing economies. In 2017, only $7 \%$ of Indians with a financial institution account accessed it from their phone or the Internet, and $2 \%$ of the population owned a mobile money account [4].

A number of large commercial banks offer mobile banking, among them: State Bank of India, Union Bank of India, PNB, ICICI, HDFC, and Axis Bank [6]. Mobile banking in India was expected to have an annual growth rate of $43 \%$ between 2012 and 2016 [7] mainly due to the rapidly growing number of cell phone users who can access $3 \mathrm{G}$ and $4 \mathrm{G}$ technologies. Mobile banking offers not only account information and payment \& transfer services but also portfolio management, general and technical support, and programs to increase affective loyalty, the feelings of the consumer for the service and a determinant of recommendation to friends and family, and behavioral loyalty [2].

\section{Literature Overview of the Theoretical Framework}

The dependent variable in the research question is the likelihood to use mobile banking in the future. This means a start for consumers who have not used Mobile Banking yet, or a continuation for those who do, which indicates behavior. The Conceptual Model of this work was inspired by a number of theories, especially TAM3 [1] and UTAUT [8]. The Technology Acceptance Model (TAM) [9], TAM2 and TAM3 are mainly about acceptance. In this work the focus is on usage, the likelihood to use, which is behavior. However, usage too implies acceptance, and many researchers have used TAM-like models with behavioral types of variables.

This work combines the TAM3 and UTAUT model. The dependent in TAM3 is Technology Acceptance, similarly to TAM. TAM3 combines TAM2 [10] and a model for determinants of perceived ease of use [11] into an overall model of technology acceptance. TAM3 aims to take into account all relevant determinants of IT adoption and use by individuals. TAM 3 has no cross-over effects. This means that determinants of perceived usefulness do not influence perceived ease of use and vice versa [1]. This work will sow considerable doubt on that (admittedly elegant) idea.

The other theoretical model that was used is the Unified Theory of Acceptance and Use of Technology (UTAUT) [8]. The dependent in UTAUT is behavioral intention as proxy for actual behavior (usage). The usage of likelihood is very close to that. In the UTAUT model three core constructs: performance expectancy, effort expectancy, and social influence, are determinants for intention. Further, facilitating conditions and intention are determinants for 
behavior. Facilitating conditions are the degree to which an individual believes that an organizational and technical infrastructure exists to support use of the system [8]. In some Theory of Planned Behavior (TPB) research, "facilitating conditions" are modeled by actual behavioral control or by its opposite, barriers, as a moderator. They block or help carrying out the intention and initiating the behavior. In UTAUT it is an antecedent of behavior. Moderators like gender, age, experience, and voluntariness of use are not used in this work.

All the theories and models contributing to UTAUT and TAM3 have been widely and successfully utilized before in a range of areas [1]. Therefore, the UTAUT construct "facilitating conditions" was also incorporated in our Conceptual Model, but as an antecedent of Perceived Ease of Use. As in UTAUT, this work focuses on intention and behavior, i.e., usage of mobile banking, and not on the abstract idea of acceptance of the technology, because this seems more socially relevant.

The conceptual model is given in Figure 1. The numbers will be discussed later; they are strengths in a network model. Remarks are: "job relevance" plays a role if mobile banking is used for work-related activities. The "subjective norm" is what the respondent thinks that people who are important to him or her will think and approve about the behavior of using mobile banking. It originated in the TPB [12] and TRA [13]. Image extends beyond brand image and was considered in this work as what general ideas the respondent has about mobile banking. Output quality is the rating of the performance of the mobile application.

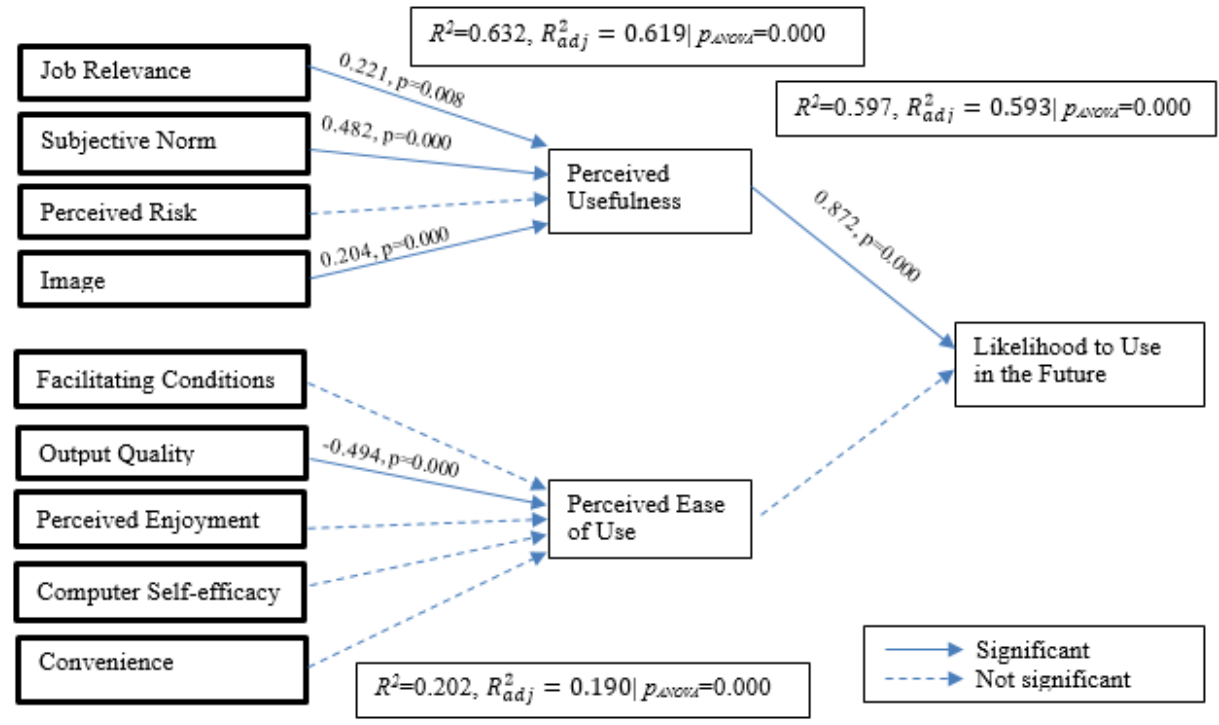

Figure 1: The original network model used in this work

\section{Methodology}

The survey consisted of two sections. The first section collected data about demographics and usage of internet and banking by the respondents. The second section consisted of questions used to measure the various independent and dependent variables. The questionnaire used structured questions, mainly in the form of a five-point Likert scale. A convenience sample of 91 respondents in India was used.

\section{Results}

\subsection{Descriptive Statistics}

In this sample $(\mathrm{N}=91), 4.4 \%$ of the respondents were below 20 years of age, $50.5 \%$ between 20 and 40, and $45.1 \%$ over 40 . Most were female, $70.3 \%$, and only $29.7 \%$ male. Only $2.2 \%$ of the respondents were retired and another $1.1 \%$ unemployed $(\mathrm{N}=90) .45 .1 \%$ had a graduate degree, and $40.7 \%$ a post-graduate, $7.7 \%$ had a doctorate, and $2.2 \%$ had another degree. Also, 
$80.2 \%$ of the respondents lived in the greater Delhi area.

Only one respondent had not used a smart phone. Smart phone usage was recent. $8.8 \%$ had used a smart phone for less than a year, $34.1 \%$ for 1 or 2 years, $41.8 \%$ for 3 to 5 years, and $14.3 \%$ for six years or longer. This recentness of smartphone use reflects the relative newness of the smart phone market in India. Of the respondents, $20.9 \%$ used internet for less than an hour a day, $37.4 \%$ for 1 to 2 hours in a day, $19.8 \%$ used internet for about 2-3 hours a day and $22.0 \%$ used it for more than 3 hours $(\mathrm{N}=91) .54 .1 \%$ of the respondents did not use banking apps on a mobile phone, while $45.1 \%$ did use it. Therefore, the sample consists mostly of respondents with a higher educational level and more female respondents living in Delhi area, who are relatively recent smart phones users, with almost half of them using mobile banking.

\subsection{Usage of Mobile Phone banking by gender}

A 2013 survey has shown that Indian women had very little knowledge of mobile financial services which is reflected in their lack of confidence or ability to use those services by themselves. For the most part, they relied on assistance to transact from a household member or an agent. In contrast, men were far more knowledgeable and used a number of services, though in small numbers, and tended to transact by themselves [14].

We used our dataset to check whether there are any differences in the way women and men do mobile banking in India. A T-test found only a few questions women's answers were on average different from men's. Women answered less affirmative on the question "I can do mobile banking without any external help" $(p=0.031)$, "Mobile banking is too complicated to use" $(p=0.007)$ and "People who are important to me think that I should do Mobile Banking" $(p=0.032)$. Women are clearly less secure about mobile banking and maybe less familiar with computers or phones in general. This led us do a Chi-square test to see if women used mobile banking different from men. The two-sided asymptotic p-value for Pearson's Chi-Square test is 0.939 , not rejecting the null-hypothesis of no differences between men and women in mobile phone usage. Table 1 shows the results. Conclusion: the stated insecurity and perceived lack of support, maybe a cultural artefact, had no influence on the participation in mobile banking.

Table 1 Chi-Square for Cross-tabulation gender*using mobile phone banking

\begin{tabular}{|l|l|l|r|r|r|}
\hline \multicolumn{2}{|c|}{} & \multicolumn{2}{|c|}{ 9) Do you currently do Mobile Banking } & \\
\cline { 3 - 6 } \multicolumn{2}{|c|}{} & Yes & No & Total \\
\hline Gender & M & Count & 12 & 15 & 27 \\
& & Expected Count & 12.2 & 14.8 & 27.0 \\
& & \% of Total & $13.2 \%$ & $16.5 \%$ & $29.7 \%$ \\
\cline { 2 - 6 } & $\mathrm{F}$ & Count & 29 & 35 & 64 \\
& & Expected Count & 28.8 & 35.2 & 64.0 \\
& & \% of Total & $31.9 \%$ & $38.5 \%$ & $70.3 \%$ \\
\hline Total & & Count & 41 & 50 & 91 \\
& & Expected Count & 41.0 & 50.0 & 91.0 \\
& & \% of Total & $45.1 \%$ & $54.9 \%$ & $100.0 \%$ \\
\hline
\end{tabular}

\subsection{The network model using the classical TAM3/UTAUT model.}

Figure 1 shows the classical unified model. Note that perceived usefulness and perceived ease of use both have their own set of antecedents. There are no antecedents that influence both mediators. As is customary, the numbers reflect the strength and significance of the explanatory variables with the dependent variable. They are the unstandardized B-coefficients in the regression equations. Paths drawn with dash arrows have non-significant coefficients. The strength of a full path can be calculated by multiplying the coefficients of the segments. 
As is often the case, perceived ease of use did not have a significant influence on acceptance (likelihood to use mobile banking). The $R^{2}$ of the regression equation for the right-hand part of the model was 0.597 , adjusted $R^{2}$ is 0.593 , indicating a large enough sample size. $P_{\text {ANOVA }}$ was 0.000. Because the strength from perceived ease of use to likelihood to use is zero, the influence of its antecedents is also zero, even if some of its antecedents would have a non-zero strength. In our sample, perceived risk had no influence on perceived usefulness. The $R^{2}$ of the regression equation for the top-left part of the model was 0.632 , adjusted $R^{2}$ is 0.619 , indicating a large enough sample size. $P_{\text {ANOVA }}$ was 0.000 .

The bottom-left part of the model had only a significant contribution from output quality. The $R^{2}$ of the regression equation for this bottom-left part of the model was 0.202 , the adjusted $R^{2}$ is 0.190 , indicating a large enough sample size because both values are close, but a disappointing explanation of the variation in perceived ease of use. $P_{\text {ANOVA }}$ was 0.000 . Note that in this result there is no path for output quality to influence likelihood to use, a somewhat counter-intuitive result. Output quality will be shown to have an influence in the next section.

\subsection{The network model allowing cross-over of antecedents of Perceived Usefulness and Perceived Ease of Use.}

Figure 2 shows that using backward regression, none of the antecedents of perceived usefulness influences perceived ease of use. A backward regression equation was used for perceived ease of use with all 9 antecedents. $R^{2}$ is a little higher because the backward analysis did not remove all remaining predictors, but they were not significant. However, the regression equation for the 9 predictors influencing perceived usefulness showed that output quality influenced perceived usefulness so strongly that it even made some predictors from the top-left part insignificant. The only two significant predictors were: output quality and the subjective norm. $R^{2}$ of the regression equation for the left part of the model influencing perceived usefulness was 0.716 , adjusted $R^{2}$ is 0.698 , indicating a large enough sample size. $P_{\text {ANOVA }}$ was 0.000 . Note that amounts to a large increase in the predictive power of the model. Output quality has two paths to influence likelihood to use, with the more obvious path blocked by the segment from perceived ease of use to likelihood to use.

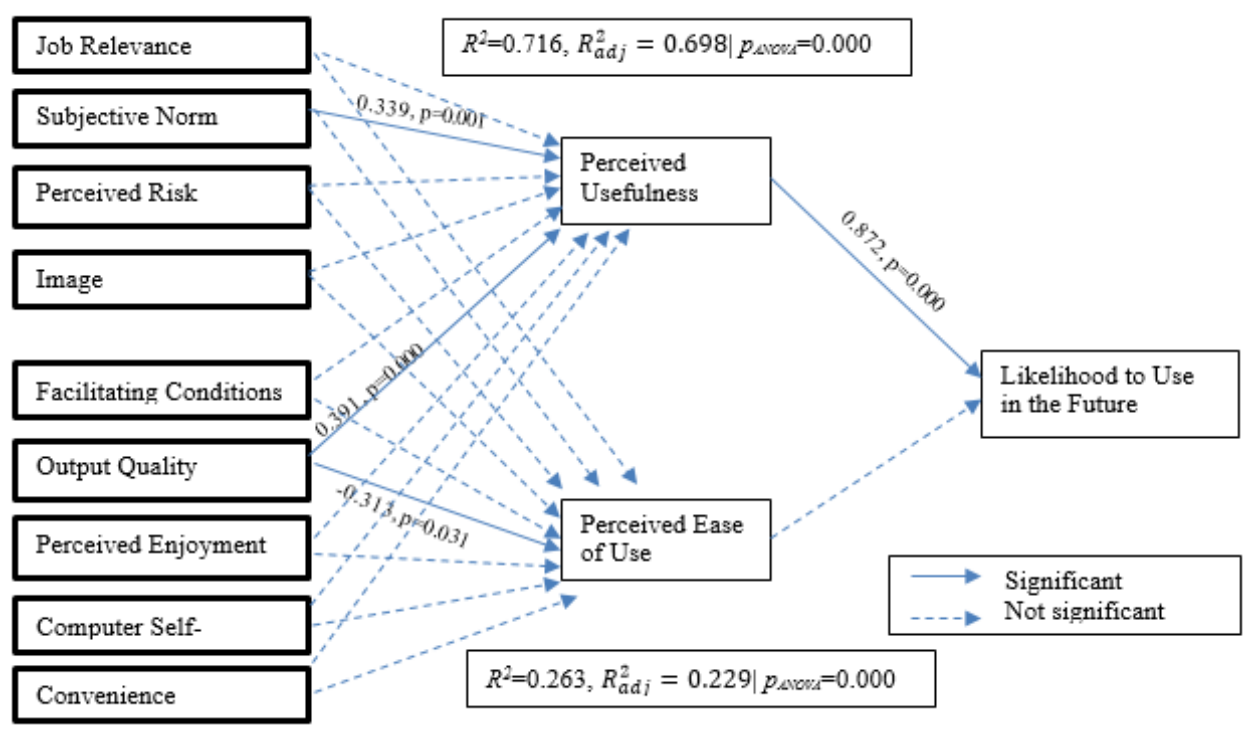

Figure 2 Network model with cross-over antecedents

5.5 The relationship between affective loyalty and likelihood to use

Standard theory predicts a relationship between satisfaction and image as predictors for 
affective loyalty. Indeed, in a backward analysis for mobile banking users only, with predictors satisfaction and image and dependent affective loyalty, image drops out, but satisfaction is a strong predictor with $R^{2}=0.624$, adjusted $R^{2}=0.605$, Beta $=0.829, p=0.000$. Standard theory also predicts a direct relationship between affective loyalty and behavioral loyalty, a construct that overlaps with the likelihood to use. Here, for mobile phone users, $R^{2}=$ is 0.695 , adjusted $R^{2}=$ is 0.687 , Beta is $0.935, p=0.000$. TAM was developed to predict the usage. This shows that it should not be used for loyalty-like predictors, or otherwise it has to be added to the model.

\section{Conclusions}

This work has shown that the UTAUT and the TAM models can be combined for the goal of explaining future usage. Additionally, we found a large and plausible cross-over effect, not predicted by the TAM3 model. Usage of mobile banking by women is not influenced by their stated insecurity. Affective loyalty is influenced by satisfaction with mobile banking and likelihood to use by affective loyalty. From a managerial point of view, the influence of peers on usage of mobile banking should not be underestimated.

\section{References}

[1] V. Venkatesh and H. Bala, "Technology Acceptance Model 3 and a Research Agenda on Interventions", Decision Sciences, Vol. 39, Issue 2, July 2008

[2] H. Sudhir, M. Pandey and I. Tiwari, "Mobile Banking in India: Barriers and Adoption Triggers", (2012)Yale School of Management, Center for Customer Insights, China Program, n.d. Internet: http://som.yale.edu/sites/default/files/files/Mbanking\%20report-Final.pdf

[3] A. Narang, Indian Women Aren't Managing Their Own Finances. Internet: https://theswaddle.com/financial-literacy-gender-gap-means-indian-women-arent-controllingpersonal-financial-management/, May 30 ${ }^{\text {th }}$ 2018[March 10 2019].

[4] A. Demirguc-Kunt, L. Klapper,D. Singer, S. Ansar and J. Hess, (2018) The Global Findex Database 2017: Measuring Financial Inclusion and the Fintech Revolution, World Bank Group, doi:10.1596/978-1-4648-1259-0, Available: https://globalfindex.worldbank.org

[5] ***, Avaya Banking Survey 2017, Available: https://www.avaya.com/en/aboutavaya/newsroom/pr-in-170809/

[6] D. Devan, "Mobile banking in India - Issues \& Challenges", International Journal of Emerging Technology and Advanced Engineering, Vol. 3, Issue 6, June 2013

[7] M. S. Velmurugan and M.S. Velmurugan, "Consumers' awareness, perceived ease of use toward information technology adoption in $3 \mathrm{G}$ mobile phones' usages in India", Asian Journal of Marketing 8(1) pp 1-23, 2014

[8] V. Venkatesh, M. G. Morris, G. B. Davis and F. D. Davis, "User Acceptance of Information Technology: Toward A Unified View". MIS Quarterly Vol. 27, No. 3, pp. 425-478, 2003

[9] F. Davis, "Perceived Usefulness, Perceived Ease of Use, and User Acceptance of Information Technology". MIS Quarterly, 13(3), 319-340, 1989.

[10] V. Venkatesh, F. D. Davis, "A Theoretical Extension of the Technology Acceptance Model: Four Longitudinal Field Studies", Management Science, Vol. 46, No. 2, pp. 186 -204, February 2000

[11] V. Venkatesh, "Determinants of perceived ease of use: Integrating control, intrinsic motivation, and emotion into the technology acceptance model", Information systems research, 11 (4), pp. 342365, December 2000.

[12] I. Ajzen, "The theory of planned behavior", Organizational Behavior and Human Decision Processes. 50 (2), pp. 179-211, December 1991. doi:10.1016/0749-5978(91)90020-T

[13] M. Fishbein and I. Ajzen, (2010), Predicting and Changing Behavior: The Reasoned Action Approach, New York: Psychology Press, https://doi.org/10.4324/9780203838020

[14] ***, Use of Mobile Financial Services Among Poor Women in Rural India and the Philippines. Internet: http://www.grameenfoundation.org/resource/use-mobile-financial-services-among-poorwomen, January 2013, [March 302019$].$ 